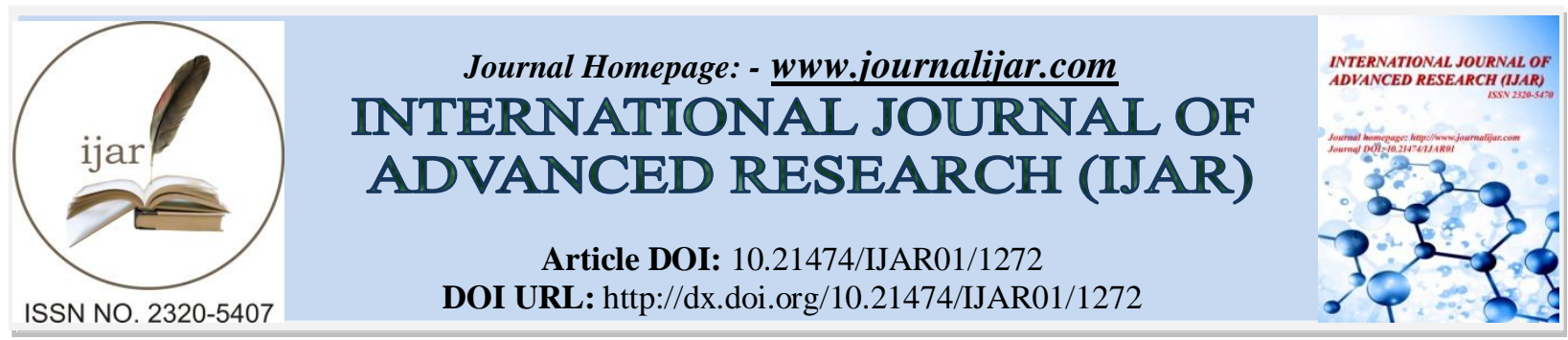

RESEARCH ARTICLE

\title{
VERTICAL DISPERSION OF CARBON MONOXIDE IN THE TROPOSPHERE.
}

\author{
R. Anjali ${ }^{1}$ and G. Mohan Kumar ${ }^{2}$. \\ 1. PG Department of Physics, N.S.S. College Pandalam, Kerala 689501, India. \\ 2. D-330, Swathi Nagar, West Fort, Thiruvananthapuram, Kerala 695023, India.
}

\section{Manuscript Info}

Manuscript History

Received: 12 June 2016

Final Accepted: 22 July 2016

Published: August 2016

Key words:-

Carbon monoxide, troposphere,

Measurements Of Pollution In The

Troposphere, Tropospheric Emission

Spectrometer, vertical profile

\begin{abstract}
Vertical distribution of carbon monoxide (CO) at different altitudes (1000-100 mb) in the troposphere over a tropical coastal site, Thiruvananthapuram $\left(8^{\circ} 29^{\prime} \mathrm{N}, 76^{\circ} 57^{\prime} \mathrm{E}\right)$ were analyzed. $\mathrm{CO}$ data from Measurements of Pollution in The Troposphere (MOPITT) and Tropospheric Emission Spectrometer (TES) for a period of 5-years from 2004-2008 were used in this study. Vertical CO profile shows a high mixing ratio at the surface $(1000 \mathrm{mb})$, decreases with increase in altitude up to $400 \mathrm{mb}$, thereafter it shows an enhancement around $\sim 300-200 \mathrm{mb}$ and again low mixing ratio up to $100 \mathrm{mb}$. CO enhancement at $\sim 300 \mathrm{mb}$ indicates the effects of deep convective systems that trap CO. Seasonal variability in vertical distribution and transport of tropospheric $\mathrm{CO}$ were monitored.
\end{abstract}

Copy Right, IJAR, 2016,. All rights reserved.

\section{Introduction:-}

Carbon monoxide (CO) is an important reactive trace gas in the Earth's atmosphere, which plays a key role in radiative forcing can be measured from space. It is a primary component of biomass burning products and also emitted by various anthropogenic activities. CO affects human and other oxygen-breathing organisms (Jiang et al. 2007). Major $\mathrm{CO}$ sinks are its oxidation by hydroxyl radical $(\mathrm{OH})$ in the troposphere, upward migration and oxidation in the stratosphere and upper layers of the atmosphere. As $\mathrm{OH}$ acts as a cleansing agent in the Earth's atmosphere, increase in $\mathrm{CO}$ mixing ratio affects the tropospheric cycles of a variety of trace gases including strong greenhouse gases like methane, ozone etc, which in turn forms adverse environmental impacts.

$\mathrm{CO}$ accumulated from the sources in the lower atmosphere migrates, by convection, turbulence and mixing, to the upper atmosphere and it oxidized to $\mathrm{CO}_{2}$. Though $\mathrm{CO}$ emission is high at the surface, it can be rapidly uplifted into mid- and upper troposphere (UT) by convection, where it can be transported around the globe by the circulation. The timescale for transport of $\mathrm{CO}$ into the lower stratosphere through upwelling advection in the tropics has been estimated to be several months (Stohl et al. 2002, Pan et al. 1995). With a lifetime of a few weeks to 2 months in the troposphere, CO acts as a good tracer of vertical transport (Lawrence et al. 2003). Vertical distribution of CO in the troposphere provides information about the middle and UT.

Global CO distribution shows spatial and temporal variation due to seasonal changes in its sources and sinks. To reduce the uncertainties in estimating $\mathrm{CO}$ sources and sinks, consistent global observations are essential. $\mathrm{CO}$ mixing ratio can be measured in-situ or remotely sensed from ground, aircraft or satellite. Aircraft and ground-based CO measurements onlv provide information on small snatial scales but satellite measurements provide a full global

Corresponding Author:- R. Anjali.

Address:- PG Department of Physics, N.S.S. College Pandalam, Kerala 689501, India. 
coverage in just a few days. Thus to obtain a complete global picture satellite observations along with ground-based or air craft measurements are needed. Satellite instruments like, Measurements Of Pollution In The Troposphere (MOPITT) onboard the EOS/Terra satellite and Tropospheric Emission Spectrometer (TES) abroad NASA's AURA satellite provide regular global observations of horizontal and vertical $\mathrm{CO}$ distribution in the troposphere.

Kar et al. (2004) reported that MOPITT CO profiles can provide significant information on vertical transport phenomena in the troposphere. In order to understand the vertical distribution of $\mathrm{CO}$ in the troposphere and hence the dispersion/transport phenomena in the troposphere, vertical profiles of CO at different pressure levels (1000-100 $\mathrm{mb}$ ) over Thiruvananthapuram from 2004-08 have been studied using MOPITT and TES CO data.

\section{Instruments:-}

Measurement of Pollution in The Troposphere (MOPITT):-

MOPITT onboard the NASA EOS-Terra satellite is a nadir view (downward looking) infrared radiometer measures $\mathrm{CO}$ and $\mathrm{CH}_{4}$. Terra is in a $705 \mathrm{~km}$, sun-synchronous orbit with a swath width of about $600 \mathrm{~km}$. Its horizontal resolution is of $22 \mathrm{~km}$ by $22 \mathrm{~km}$. The primary objective of MOPITT is to enhance knowledge of the lower atmosphere system and particularly interactions with the surface/ocean/biomass systems. MOPITT uses gas correlation spectroscopy in six channels (US EPA 1995) for CO in two distinct bands: the solar band at $2.3 \mu \mathrm{m}$ consisting of two Length Modulated Cell (LMC) channels and the thermal band at $4.7 \mu \mathrm{m}$ comprising of two LMC and two Pressure Modulated Cell (PMC) channels. Each channel measurement provides two signals, the average and the difference signal, details of which have been available elsewhere (Schoeberl et al. 2006, Ho et al 2005).

\section{Tropospheric Emission Spectrometer (TES):-}

TES is an infrared, high-resolution, Fourier transform spectrometer (Beer et al. 2001, 2006) abroad NASA's AURA satellite at an altitude of $705 \mathrm{~km}$. Aura is in a sun-synchronous orbit that brings the satellite over each latitude at the same local solar mean time each day. TES observes both straight down (nadir view) and at a sideways angle (limb view) behind the satellite and covers the spectral range $650-3050 \mathrm{~cm}(3.3-15.4 \mathrm{~m})$ at a spectral resolution of $0.1 \mathrm{~cm}$ (nadir viewing) or $0.025 \mathrm{~cm}$ (limb viewing). High spectral resolution of TES enables it to identify the wavelengths at which the substances are emitting and thus the precise identification of the substances also provides information about their location in the atmosphere. Emission wavelengths can vary with temperature and pressure. Thus seeing the emissions with great precision facilitates scientists to infer the temperature and pressure of the chemicals from which they came. More details are available elsewhere (Beer et al. 2006)

\section{Data analysis:-}

In the present study we have used MOPITT level 3 data. MOPITT level 3 (gridded CO data) provides gridded global CO distribution (global map) of different tropospheric layers (1000 mb (surface), 900, 800,700, 600, 500, 400 ,300, 200 and $100 \mathrm{mb}$ ) produced by mapping procedures and data assimilation models. MOPITT data are provided in EOS-HDF format and is freely available for download from the NASA Langley DAAC via the World Wide Web (http://eosweb.larc.nasa.gov/ PRODOCS/mopitt/table_mopitt.html). TES version V002 CO data was also used for obtaining the vertical profile of CO in the troposphere at different pressure levels $(1000,825,681,464,316,215$ and $100 \mathrm{mb})$.

\section{Results and discussions:-}

\section{Vertical distribution of $\mathrm{CO}$ in the troposphere:-}

Vertical profiles of CO at different pressure levels (1000-100 mb) in the troposphere over Thiruvananthapuram for a period of 2004-08 have been monitored. From Fig. 1 to Fig. 4, it has been seen that CO mixing ratio decreased with increase in altitude (decrease in pressure) as vertical mixing occurs between the polluted boundary layer and the cleaner free troposphere. Fig. 2(a)-(b) to 4 (a)-(f) present the MOPITT and TES vertical CO profile from 20062008. It shows that $\mathrm{CO}$ mixing ratio is maximum at the surface (1000 mb pressure), decreases with increase in altitude up to $400 \mathrm{mb}(\sim 7 \mathrm{~km})$, an enhancement around 300-200 $\mathrm{mb}(\sim 9-12 \mathrm{~km})$ and again low mixing ratio up to $100 \mathrm{mb}(\sim 16 \mathrm{~km}$ altitude). Since most of the natural as well as anthropogenic CO sources are situated at the surface, $\mathrm{CO}$ mixing ratio at the surface is high compared to high altitudes in the troposphere. As goes to higher layers of the atmosphere a sudden decrease in CO mixing ratio is found at $800 \mathrm{mb}$. CO mixing ratio at $800 \mathrm{mb}$ is found to be less by $\sim 40 \mathrm{ppb}$ from that of $1000 \mathrm{mb}$. The decrease in $\mathrm{CO}$ mixing ratio with altitude continues up to $300 \mathrm{mb}$.

Enhancement in CO mixing ratio observed around $\sim 300 \mathrm{mb}$ compared to nearby pressure levels could be due to the deep convection systems at this level (Kar 2004). From Fig. 2 to Fig.4, it is seen that both MOPITT as well as TES shows the enhancement around $300-200 \mathrm{mb}$. This enhancement is due to a strong trapping effect by Asian Summer 
Monsoon (ASM) anti-cyclone (Liang et al 2006). Recent studies have suggested that deep convection associated with the ASM often lifts boundary layer pollution from India, Southeast Asia, and South China into the UT followed by westward transport by the tropical easterly jet to over the Middle East (Liang et al 2006) and the Mediterranea (Li et al. 2005). Deep convection can cause rapid injection of boundary layer CO into the UT. Kar et al. (2004) reported the CO plumes have been observed in the UT across South Asia in summer. 3D chemistry transport models also indicate that deep convection during the summer monsoon in the Indian subcontinent can lift boundary layer pollutions to the UT leading to a plume of enhanced CO levels in the $400-150 \mathrm{mb}$ range (Lelieveld et al. 2002). Kar et.al (2004) and Liang et al.(2006) also reported the ASM plume in upper tropospheric CO as evidence of deep convection effects in MOPITT retrievals.

\section{Seasonal variation of $\mathrm{CO}$ vertical distribution:-}

MOPITT and TES measurements show a high degree of seasonal variability in vertical CO distribution. CO from surface (1000 mb) to $600 \mathrm{mb}$ (Fig. 1 to Fig. 4) shows high CO mixing ratio in winter (December to February), when photochemistry is least active and drops in summer (April-May) while $\mathrm{OH}$ concentrations increase. Whereas $\mathrm{CO}$ mixing ratio at this altitudes during monsoon (June-August) is found to be least compared to winter and summer due to deep convections associated with monsoon. However, a least significant seasonal variation of CO mixing ratio is observed for 500-100 mb (upper troposphere). Kar et al. (2004), Lawrence et al. (2003) reported that mixed layer height variation plays an important role in the transport and mixing of trace gases in lower atmosphere up to around $\sim 3 \mathrm{~km}$ (700 mb pressure level), where as this effect diminishes with increasing altitude.

Fig. 1 to Fig. 4 shows a large difference in $\mathrm{CO}$ mixing ratio between surface and $800 \mathrm{mb}$. The difference in $\mathrm{CO}$ mixing ratio between the adjacent pressure layers, which indicates variations in vertical transport of $\mathrm{CO}$ with altitude. This difference in CO mixing ratio can also be seen at high altitudes ( $800 \mathrm{mb}$ to $100 \mathrm{mb}$ ) but it decreases with increase in altitude (Fig. 1 to Fig. 4). Seasonal variation in $\mathrm{CO}$ mixing ratio between the adjacent pressure layers indicates seasonal variation in vertical transport of $\mathrm{CO}$ from the surface to high altitude. Difference in $\mathrm{CO}$ mixing ratio between the adjacent pressure layers is found to be high during winter compared to summer and monsoon, showing $\mathrm{CO}$ vertical transport from the surface to high altitude is less during winter compared to summer and monsoon. This could be due to low boundary layer height in winter, which traps $\mathrm{CO}$ low to the ground. Jiang et al. (2007) established that CO mixing ratio in the UT is relatively weak despite of strong biomass burning events, mainly due to the lack of deep convection directly over the emission source. While the difference in CO mixing ratio between adjacent pressure layers is found to be low during monsoon compared to summer, indicates a high CO vertical transport during monsoon. This might be due to the strong atmospheric circulations associated with monsoon. Modeling analyses showed that distribution, seasonal variation and transport of $\mathrm{CO}$ can vary significantly at different altitudes (Liu et al. 2007, Tolton et al. 1997) but substantial differences exist between models in which the simulated UT CO shows different behavior in seasonally (Kar et al. 2004).

From Fig. 1 to Fig. 4, it can be seen that the enhancement in CO mixing ratio around 300-200 mb is high during summer and monsoon and less pronounced during winter. As this enhancement is due to TEJ (Tropospheric Easterly Jet), which is associated with Indian summer monsoon, CO mixing ratio around 300-200 mb is very high during monsoon compared to summer. The trajectory analysis over two major Indian cities revealed that the deep convection around 300-200 mb can lift the boundary layer air to the upper troposphere in 2-5 days (Kar et al., 2004). It is also seen that unlike winter and summer, $\mathrm{CO}$ mixing ratio around $300-200 \mathrm{mb}$ in monsoon is high compared to CO mixing ratio at lower altitudes $(600-825 \mathrm{mb})$, except ground level. The strong rise of CO mixing ratio at this layer is due to the deep convective activities around $300 \mathrm{mb}$ level during monsoon (Lawrence et al. 2003). Jiang et al. 2007 also reported that the deep convection over land associated with the ASM carries a large amount of anthropogenic pollutants boundary layer air into the UT, resulting in high CO over South Asia.

Annual variation of MOPITT and TES CO at the surface is shown in Fig. 5(a) and (b) respectively. It has been seen that annual variation of both MOPITT and TES CO at the surface follows a U- shape pattern with high in winter and low during summer and monsoon. Annual variations of MOPITT and TES CO at 100-800 mb, shown in Fig. 6(a) (f) and 7 (a) - (f). It shows that annual variation of $\mathrm{CO}$ mixing ratio at $800 \mathrm{mb}$ follows a $\mathrm{U}$ - shape pattern like $\mathrm{CO}$ at the surface. CO annual variation from $600-100 \mathrm{mb}$ shows high CO in winter (Dec-Jan) and low in summer and monsoon. But CO mixing ratio in summer (April) is slightly higher than that of the preceding months (Feb-March). 


\section{Vertical dispersion of $\mathrm{CO}$ in troposphere:-}

Seasonal variation of $\mathrm{CO}$ at the surface shows high mixing ratio during the end of winter (January-February). Seasonal variation of $\mathrm{CO}$ in the middle and UT shows high mixing ratio in April compared to the preceding months March and February (Fig. 6 (a)- (f)) CO mixing ratio in the troposphere retrieved from TES (Figure 7 (a)-(f)) also shows high CO in April compared to March. MOPITT as well as TES CO measurements over Thiruvananthapuram shows that CO mixing ratio from 700-100 mb is high in April compared to the preceding month March.

A massive biomass burning event takes place at Thiruvananthapuram in every year as a part of a religious festival called Pongala. Pongala celebrates in the last week of February or in the first week of March in every year. Anjali et al. (2009) reported a massive enhancement in surface CO mixing ratio at Thiruvanathapuram during the Pongala. MOPITT and TES measurements shows high CO mixing ratio in February or March. Pongala could be the possible reason for this high $\mathrm{CO}$ over Thiruvananthapuram in February/March. Since the measurement site at which the analyzer installed is about $\sim 8 \mathrm{~km}$ away from the Pongala sites, the wind effect has a major role in the transport of high CO produced at the burning sites to the measurement site. The terrain of the measurement site is hilly with a hillock to the northeast and southeast. Due to this topography, $\mathrm{CO}$ transported to the measurement site from the Pogala site is very less. CO analyzer installed at the above mentioned measurement site shows a less pronounced CO mixing ratio in 2005, 2006 and 2008 than when it was installed near to the Pongala sites (2004 and 2007). Hence the satellite $\mathrm{CO}$ measurements show high monthly mean $\mathrm{CO}$ in the month of Pongala (February/March) compared to ground-based $\mathrm{CO}$ measurements.

CO mixing ratio from surface to $800 \mathrm{mb}$ in March is higher than that of April (Fig. 6 (a) - (f)). While in April, CO mixing ratio from 700-100 mb is high compared to March and other months including winter months. It can also be seen that, there is no enhancement in $\mathrm{CO}$ mixing ratio at the surface during April. Hence it is clear that high $\mathrm{CO}$ in the middle and UT observed in April is not due to the transport of $\mathrm{CO}$ from the surface during the nearby days but it is due to the vertical transport of high CO produced at the surface during Pongala in March. This shows that high $\mathrm{CO}$ produced at the surface during Pongala in March takes nearly a month to get transported to the high altitudes in the troposphere from the surface.

Fig. 8 presents the vertical profile of CO in the troposphere from March 032007 (Pogala day) to April 022007. High CO mixing ratio is seen at the surface compared to the previous and the days after the Pongala event. An enhancement in CO from surface $(1000 \mathrm{mb})$ to $700 \mathrm{mb}$ is also seen during the Pongala day. It shows high CO produced at the surface $(1000 \mathrm{mb})$ get dispersed to $\sim 3 \mathrm{~km}$ altitude $(700 \mathrm{mb})$ within 24 hours. CO enhancement at $600 \mathrm{mb}$ to $400 \mathrm{mb}$ is seen on 20 March 2004, 17 days after high CO emission at the surface due to Pongala. Enhancement in CO at 300-100 mb ( $9 \mathrm{~km}$ to $16 \mathrm{~km}$ altitude), seen on 02 April 2004 indicating that the high CO in the middle troposphere (700-400 mb) takes another 12 days to get transported to the UT (100 mb or $16 \mathrm{~km}$ altitude). In general $\mathrm{CO}$ produced at the surface took nearly a month to get dispersed to the UT (16 km altitude or $100 \mathrm{mb}$ pressure layer) during March- April.

Vertical CO distribution in the troposphere in a summer month (May 2008) is shown in Fig. 9. It shows high CO mixing ratio at the surface and up to $800 \mathrm{mb}$ on 01 May 2008.CO enhancement at 700-300 mb is seen on 07 May 2008, 7 days after CO enhancement in the lower troposphere. While an enhancement in CO at 300-100 mb is seen on 15 may 2008, showing it takes another 8 days to transport CO from middle troposphere to UT. Hence, during summer CO dispersion from the surface to UT takes nearly 15 days, which is less than those ( 30days) in March. As MOPITT CO data was not available on days with high $\mathrm{CO}$ emission over Thiruvananthapuram during events like forest fire, massive biomass burning etc. in winter and monsoon during the measurement period, we could not monitor the vertical dispersion of $\mathrm{CO}$ during winter and monsoon. But variation in vertical dispersion of $\mathrm{CO}$ during March and May (Fig. 8 and Fig. 9) shows that vertical dispersion of CO varies seasonally. Temporal variation in vertical dispersion of $\mathrm{CO}$ in the troposphere depends on the seasonal changes in the troposphere. So it is clear that like CO horizontal transport, vertical transport of CO from the surface to UT also depends on the boundary layer movements and atmospheric circulations, which varies seasonally.

\section{Figure captions:-}

1. Figure 1(b). TES CO vertical profile in 2006

2. Figure 2(a). MOPITT CO vertical profile in 2007

3. Figure 2(b). TES CO vertical profile in 2007 
4. Figure 3(a). MOPITT CO vertical profile in 2008

5. Figure 3(b). TES CO vertical profile in 2008

6. Figure 4 (a) Annual variation of MOPITT $\mathrm{CO}$ at the surface

7. Figure 4 (b) Annual variation of TES CO at the surface

8. Figure 5(a)-(f). Annual variation of MOPITT CO in the troposphere from $100 \mathrm{mb}$ to $800 \mathrm{mb}$ ( in panels respectively from left to right)

9. Figure 6 (a)-(f). Annual variation of TES CO in the troposphere from $100 \mathrm{mb}$ to $800 \mathrm{mb}$ ( in panels respectively from left to right)

10. Figure 7. Vertical CO distribution from March 032007 (Pogala day) to April 112007

11. Figure 8. Vertical CO distribution during May 2008
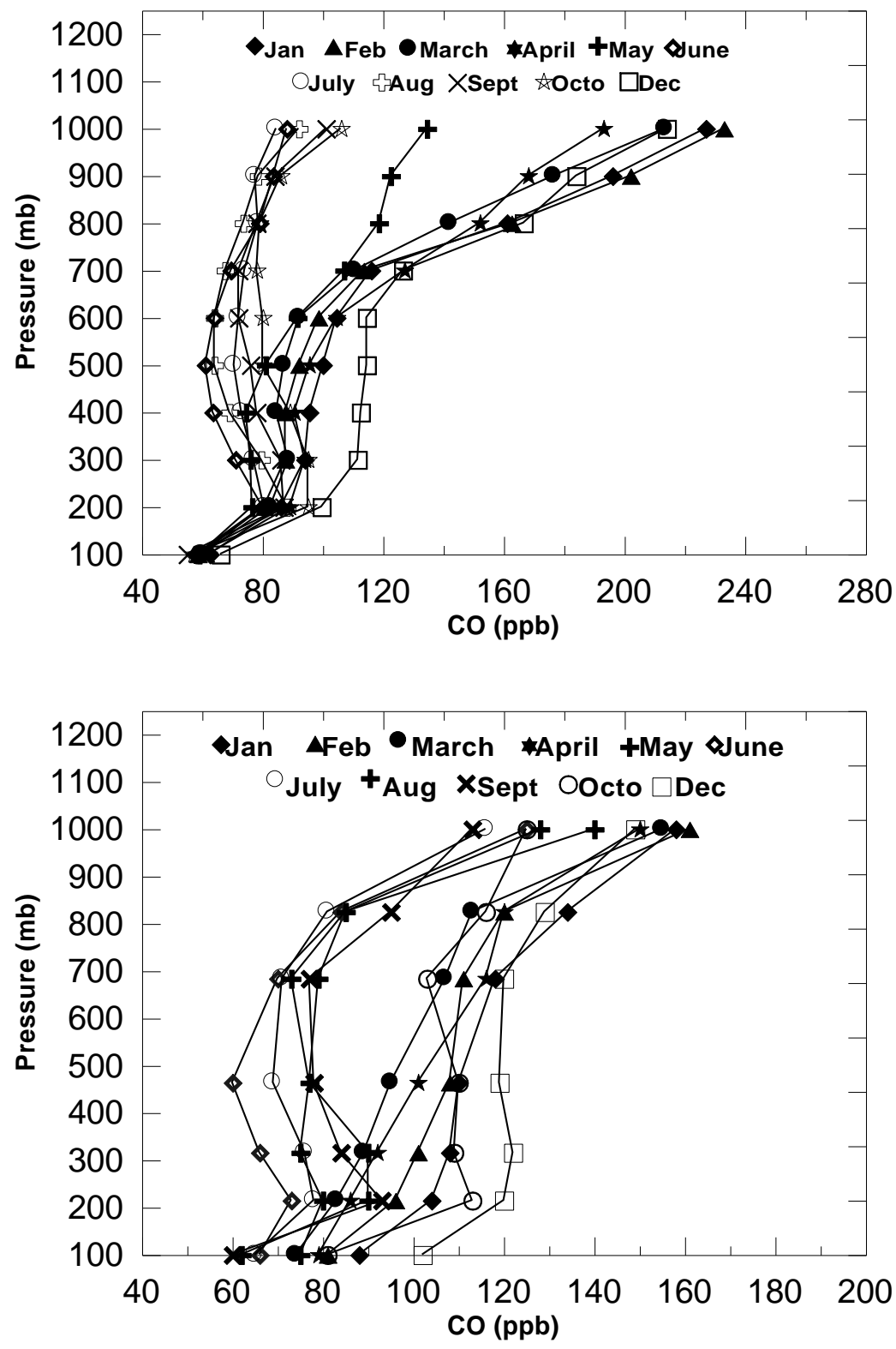

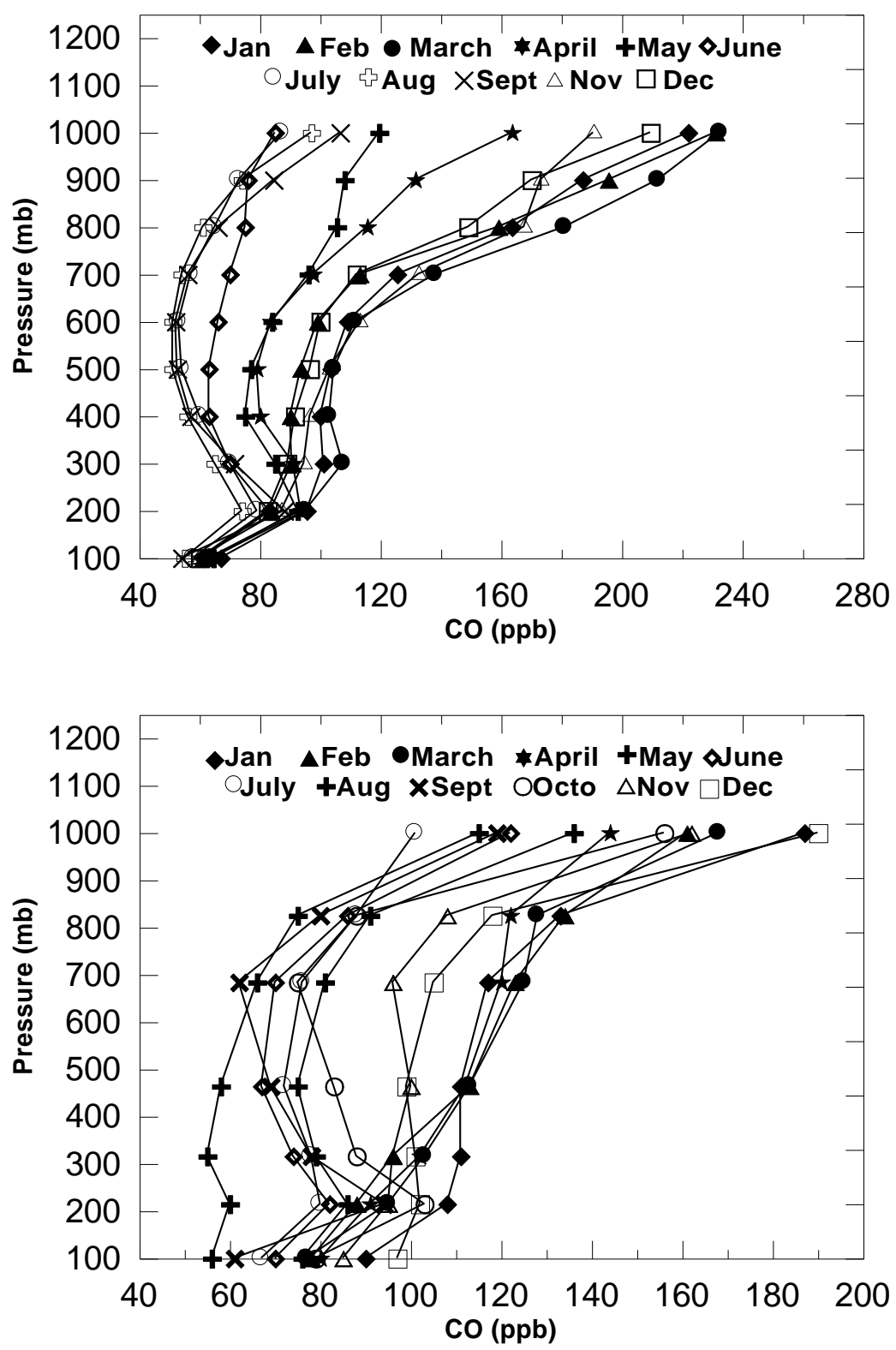

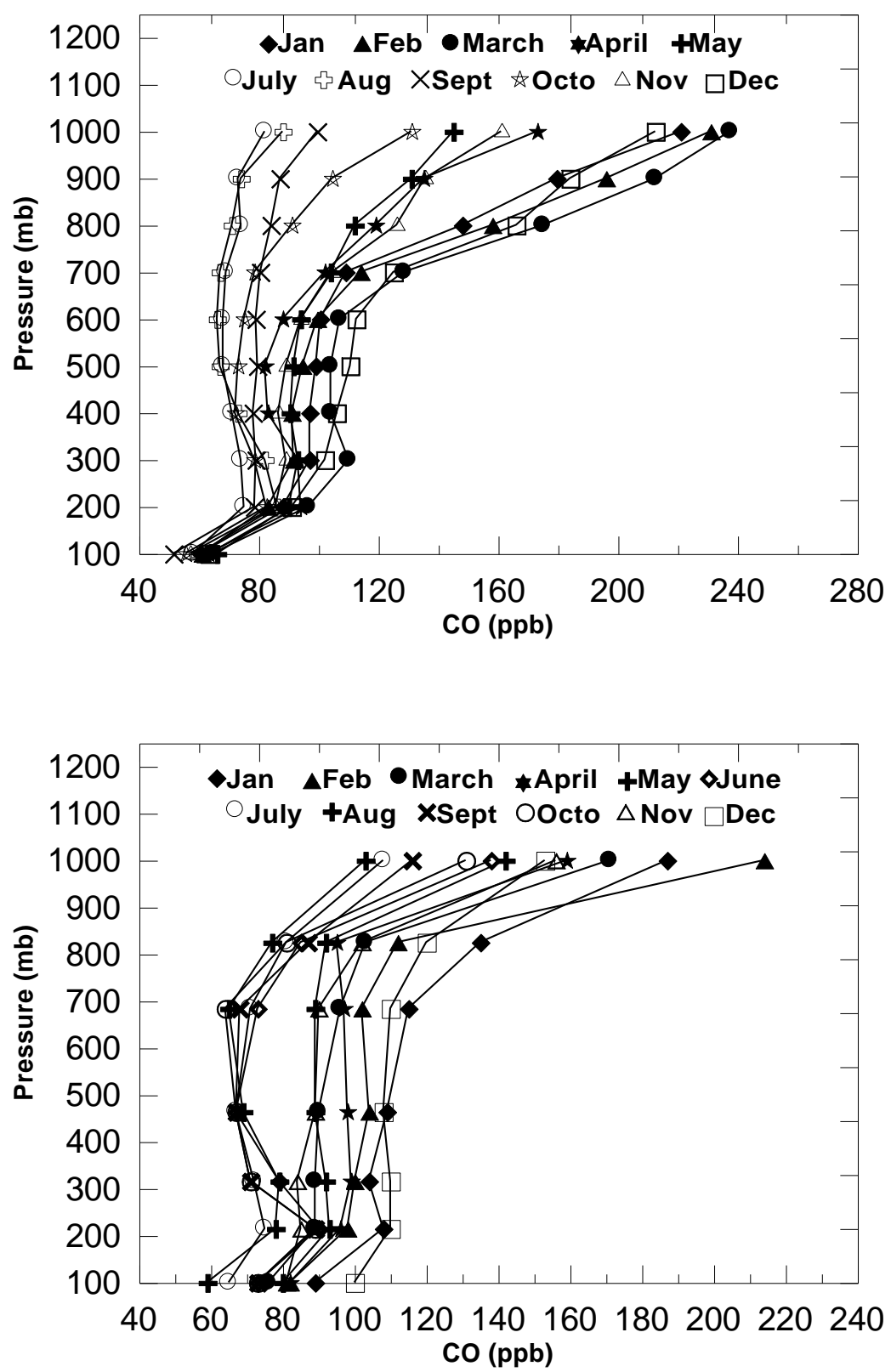

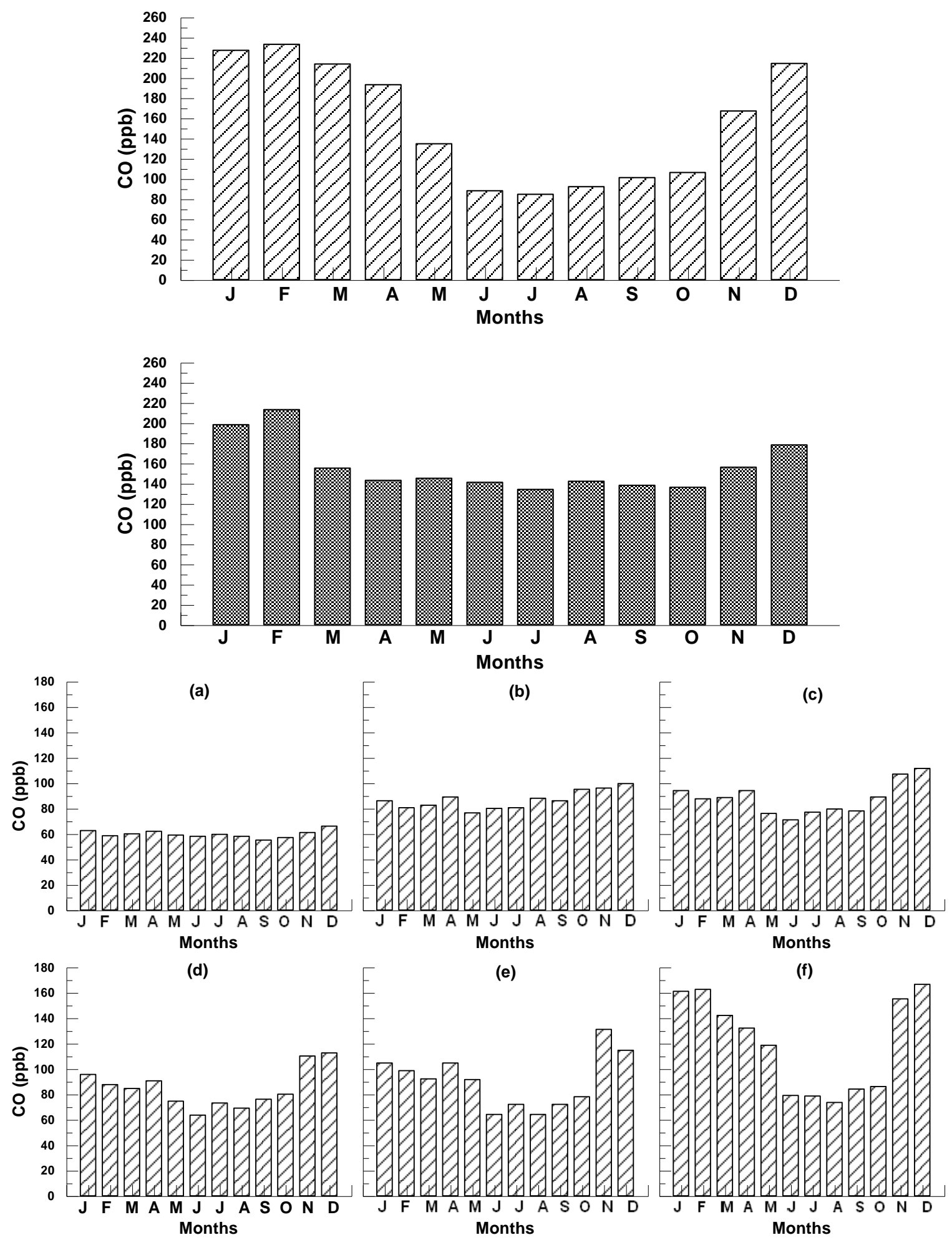

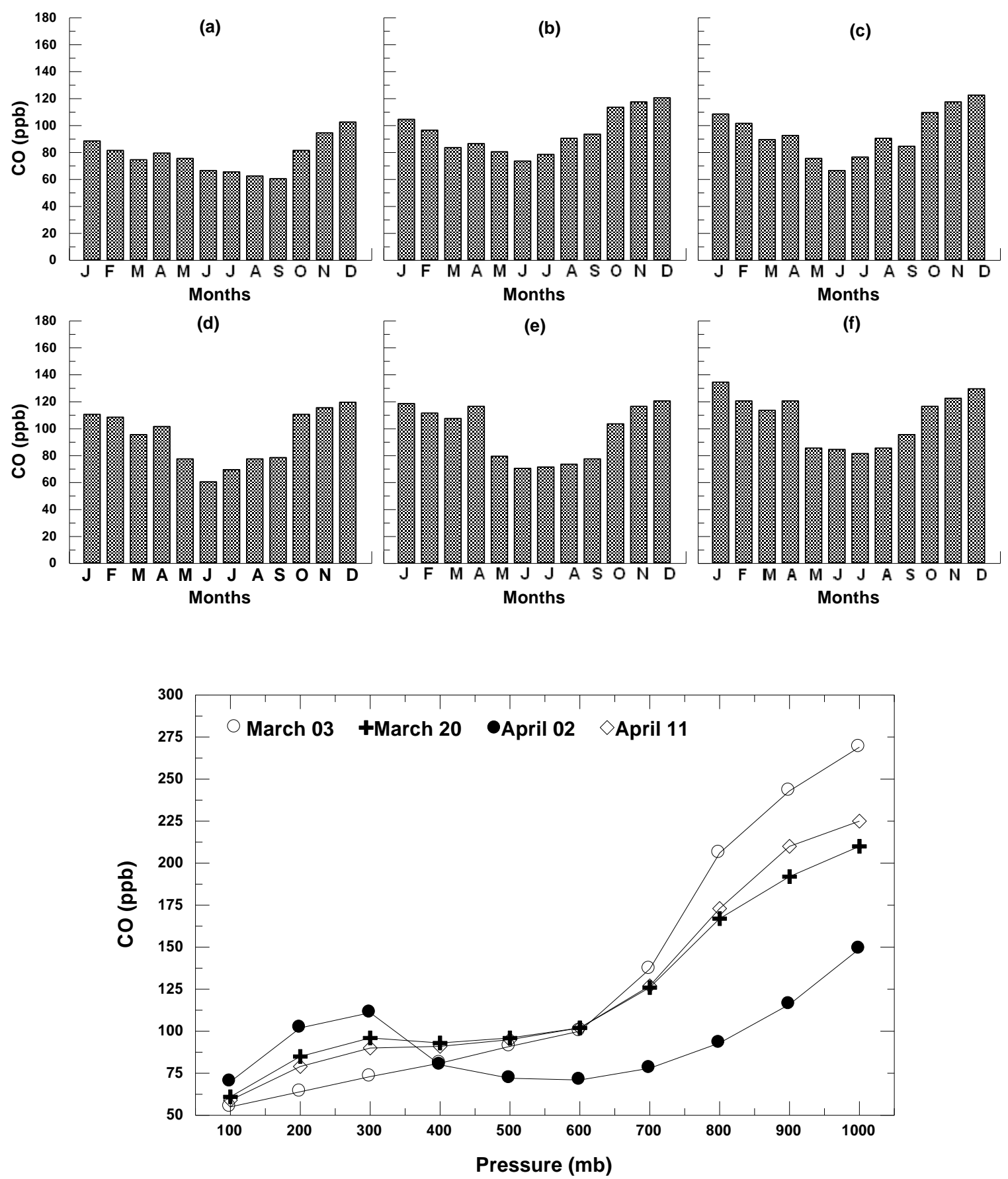


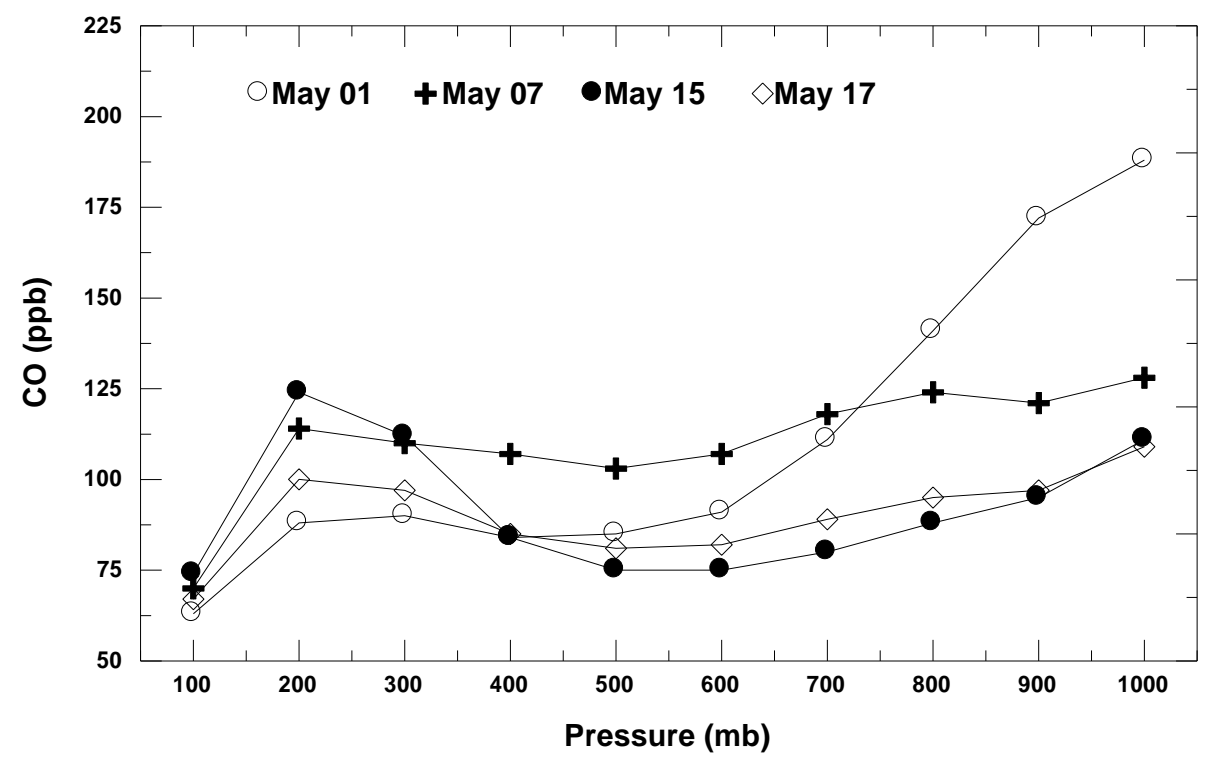

\section{Conclusions:-}

CO vertical profiles $(1000-100 \mathrm{mb})$ in the troposphere over Thiruvananthapuram from 2004-08 were studied using MOPITT and TES measurements. Study results showed that CO mixing ratio decreased with altitude (decrease in pressure) in the troposphere. High CO found at the surface $(1000 \mathrm{mb})$ decreased with altitude up to $400 \mathrm{mb}$ and showed an enhancement around 300-200 mb and again low CO up to $100 \mathrm{mb}$. CO vertical profiles showed high seasonal variation with high during winter and low during summer and monsoon. Since CO enhancement around 300-200 mb is due to TEJ, which is associated with Indian summer-monsoon, CO mixing ratio around 300-200 mb is very high during monsoon compared to summer and is less pronounced in winter. CO mixing ratio at 300-200 mb in monsoon was high compared to lower altitudes (600-825 mb), except ground level. Strong atmospheric circulations associated with monsoon cause high vertical transport of CO in monsoon compared to other seasons. High CO emitted at the surface over Thiruvananthapuram during the Pongala took nearly a month to get dispersed to the UT in March. But in a summer month high CO produced at the surface over Thiruvananthapuram took $\sim 15$ days to get transported to the UT. It indicated a seasonal variation in the vertical dispersion of CO. From this study, it is clear that $\mathrm{CO}$ vertical profile could provide significant information on vertical transport phenomena in the troposphere.

\section{Acknowledgments:-}

The authors are grateful to the Indian Space Research Organization (ISRO), Government of India for funding this project under their Geosphere Biosphere Programme through the Space Physics Laboratory, Vikram Sarabhai Space Centre, Thiruvananthapuram and the Director, CESS for providing all support.

\section{References:-}

1. Anjali, R, Mohan Kumar, G. and Sampath, S. (2009): Observed local enhancements in atmospheric carbon monoxide during biomass burning events, J. Ind Geophys. Union, 13, 149-158.

2. Beer R., Glavich, T. A. and Rider, D. M. (2001): Tropospheric Emission Spectrometer for the Earth Observing System's Aura satellite. Appl. Opt., 40, 2356-2367

3. Beer, R. (2006): TES on the Aura mission: Scientific objectives, measurements and analysis overview IEEE Trans. Geosci. Remote Sens, 44, 1102-1105

4. Ho, S. P., Edwards, D. P., Gille, J. C., Luo, J. A., Osterman, M., Kulawik, G. B., and Worden, H., Global comparison of carbon monoxide profiles and column amounts from Tropospheric Emission Spectrometer (TES) and Measurements of Pollution in the Troposphere (MOPITT). J. Geophys. Res., 110, D21308, doi:10.1029/2005JD005946

5. James A. R., Monique M. N., Neil B. H., Stephen R. T. (2000): Carbon monoxide poisoning - a public health perspective. Toxicology, 145 (1), 1-14

6. Jiang, J. H., Livesey, N. J., and Su, H. (2007): Connecting surface emissions, convective uplifting, and longrange transport of carbon monoxide in the upper-troposphere: New observations from the Aura Microwave Limb Sounder. J. Geophys.Res., 34, L18812, doi:10.1029/2007GL030638 
7. Kar, J., Bremer, H., Drummond J. R., et al. (2004): Evidence of vertical transport of carbon monoxide from Measurements of Pollution in the Troposphere (MOPITT). Goe.phy.res. Letters, 31, L23105, doi:10.1029/2004GL021128

8. Lawrence, M. G., Rasch, P. J. von Kuhlmann, R. Williams, J. (2003): Global chemical weather forecasts for field campaign planning: predictions and observations of largescale features during MINOS, CONTRACE, and INDOEX, Atmos. Chem. Phys. 3, 267-289

9. Lelieveld, J., Berresheim, H., Borrmann, S., Crutzen, P. J., Dentener, F. J., Fischer, H., Feichter, J., Flatau, P. J. (2002): Global air pollution crossroads over the Mediterranean, Science, 298, 794-799

10. Li, Q. B., Jiang, J. H., Wu, D. L., Read, W. G. (2005): Convective outflow of South Asian pollution: A global CTM simulation compared with EOS MLS observations. Geophys. Res. Lett., 32, L14826, doi:10.1029/2005GL022762

11. Liang Q., L. Jaegl, D. A. Jaffe, P. Weiss-Penzias (2006): Long-range transport of Asian pollution to the northeast Pacific: Seasonal variations and transport pathways of carbon monoxide. J. Geophys. Res. 109, D23S07, doi:10.1029/2003JD004402

12. Liu, C., E., Zipser, T., Garrett, J. H. Jiang, Su, H., How do the water vapor and carbon monoxide "tape recorder" start near the tropical tropopause? Geophys. Res. Lett., ,2007, 34, L09804, doi:10.1029/ 2006GL029234

13. Pan, L., Edwards, D. P., Gille, J. C., Smith, M. W. and Drummond, J. R. (1995): Satellite remote sensing of tropospheric $\mathrm{CO}$ and $\mathrm{CH}_{4}$ : Forward model studies for the MOPITT instrument, Appl. Opt., 34, 6976-6988.

14. Schoeberl, M. R., Duncan, B. N., Douglass, A. R. Waters, J. (2006): The carbon monoxide tape recorder. Geophys. Res. Lett., 33, L12811, doi:10.1029/2006GL026178

15. Stohl, A., Eckhardt, S., Forster, C., James, P., Spichtinger, N. and Seibert,P. (2002): A replacement for simple back trajectory calculations in the interpretation of atmospheric trace substance measurements, Atmos. Env., 36, 4635-4648.

16. Tolton, B. T., and Drummond J. R.: Characterization of the lengthmodulated radiometer. Appl. Opt., doi:10.1364/ AO.36.005409, 36, 5409 - 5419,

17. U.S. Environmental Protection Agency (EPA) (1995): National air pollution emission trends, 1900-1994, Rep. EPA-454/R-95-011, Washington D.C. 